\title{
Correction to: Compensatory motion scaling for time-delayed robotic surgery
}

Ryan K. Orosco ${ }^{1}$ - Benjamin Lurie ${ }^{1} \cdot$ Tokio Matsuzaki $^{2}$ - Emily K. Funk ${ }^{1} \cdot$ Vasu Divi $^{3} \cdot$ F. Christopher Holsinger ${ }^{3}$. Steven Hong ${ }^{4} \cdot$ Florian Richter $^{5} \cdot$ Nikhil Das $^{5} \cdot$ Michael Yip $^{5}$

Published online: 21 July 2020

(C) Springer Science+Business Media, LLC, part of Springer Nature 2020

\section{Correction to: Surgical Endoscopy} https://doi.org/10.1007/s00464-020-07681-7

This article was updated to correct Tokio Matsuzaki's name in author listing.

Publisher's Note Springer Nature remains neutral with regard to jurisdictional claims in published maps and institutional affiliations.

The original article can be found online at https://doi.org/10.1007/ s00464-020-07681-7.

Ryan K. Orosco

rorosco@health.ucsd.edu

1 Division of Head and Neck Surgery, Department of Surgery, Moores Cancer Center, University of California San Diego, San Diego, CA, USA

2 Department of Cardiac Surgery, Japan Biodesign Program, The University of Tokyo, Tokyo, Japan

3 Department of Otolaryngology, Stanford University, Stanford, CA, USA

4 Division of Otolaryngology, Walter Reed National Military Medical Center, Bethesda, MD, USA

5 Department of Electrical and Computer Engineering, University of California San Diego, San Diego, CA, USA 